\title{
Idiopathic Facial Nerve Paralysis \& Response to Physiotherapy in Pregnant Woman; A Case Report
}

${ }^{1}$ Wajida Perveen, ${ }^{2}$ Muhammad Akhtar, ${ }^{3}$ Riaz Hashmi, ${ }^{1}$ Misbah Amanat Ali,

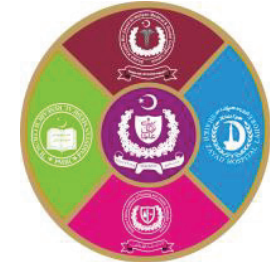

${ }^{4}$ Sahreen Anwar, ${ }^{5}$ Ayesha Ghani

${ }^{I}$ Department of Physical Therapy, Sialkot College of Physical Therapy, Amin Welfare \& Teaching Hospital, Sialkot

${ }^{2}$ Department of Department of Physical Therapy, University of Lahore

${ }^{3}$ Department of Physical Therapy, Syed Medical Complex, Sialkot

${ }^{4}$ Department of Physical Therapy, Independent Medical College, Faisalabad

${ }^{5}$ Department of Gynecology \& Obstetrics, Madina Teaching Hospital, Faisalabad.

\begin{abstract}
Facial nerve palsy is a common condition affecting both genders and all age group. However, its incidence in pregnant females needs greater care. It may affect only lower half of the face or full one side of the face or in extreme condition bilateral sides. Symptoms include deviation of angle of mouth towards sound side, flattening of nasolabial folds, loss of forehead wrinkles and inability to completely close the eyelid along with loss of taste on anterior two third of tongue. Here we present a rare case report of facial nerve palsy in a pregnant woman in third trimester of pregnancy. She was offered an evidence based physiotherapy treatment regime along with pharmacological treatment and she recovered; however late complication of "Ptosis" was reported.
\end{abstract}

Key words: Facial Palsy, Bell's palsy, Pregnant Women, Ptosis, Neurodynamic Techniques, Facial Disability Index (FDI), Sunny Brook Facial Grading System (SB FGS).

\section{INTRODUCTION}

$\mathrm{S}_{\mathrm{ir}}$ William Gower defined facial paralysis as "The loss of motion of all the muscle supplied by $7^{\text {th }}$ cranial nerve (facial nerve) on one side. Most of the times it happens without ear infection or injury close to the nerve after it arises, it implies disease of the nerve as it passes through the bone. ${ }^{1}$ Idiopathic bilateral loss of motion of facial muscles, albeit uncommon, seems to be more frequent during the last trimester of pregnancy and in the early puerperium. Bilateral facial paralysis is less regularly idiopathic, and different etiologies had been found. ${ }^{2}$ Onset is usually painful and acute, viral inflammation, immunosuppressant features of pregnancy and higher extracellular fluid content may be predisposing factor of the condition. ${ }^{3}$

Facial paralysis in pregnancy is related with gestational and fetal difficulties, especially in the third trimester. Sir Charles Bell in 1830 first identified a potential relationship of pregnancy with loss of movement of the muscles of facial expressions. ${ }^{4}$ In a case series reported, eight cases of pregnancy associated bell's palsy (PABP) from 2006 to 2016, were identified out of them seven were found in third trimester and only one started two days postpartum. The recovery of these cases was satisfactory. ${ }^{5}$ But another study reported that, Prognosis of the women with Bell's palsy in pregnancy is worse than that of the non-pregnant cases. ${ }^{6}$

\section{CASE REPORT}

A 32 years old female gravida 3 was in $36^{\text {th }}$ week of her pregnancy. She woke up in the morning and found his mouth deviated to right side. Her left eye lid was not closing completely, nasolabial folds were lost, and she was unable to produce wrinkles on left side of her forehead. The whole left half of the face was flat and expressionless. Also there was loss of taste sensation on tongue, difficulty in drinking, chewing and swallowing. On the same day she visited her physician, who advised to take preventive and protective measures (especially eye care) only and referred to visit physiotherapist till delivery. She could not visit to physiotherapist but observed precautions at home. After seven days she gave birth to a normal healthy baby girl at $37^{\text {th }}$ week of pregnancy who was 5.8 pounds. She was a known case of anxiety and depression since last five years and was also suffering from pregnancy induced hypertension. Physiotherapy treatment was started on $3^{\text {rd }}$ day of delivery after ten days of the 
onset of symptoms. Treatment included electric stimulation, support for the paralyzed facial muscles (provided by Kinesiotaping) to prevent contracture on good side and overstretching of the facial muscles of affected side (Left), exercises for facial muscles of left side three times a week. She was educated to self-administer home exercise programme according to condition of muscles. In the mean while neurophysician was consulted, who advised corticosteroids along with other pharmacological treatment. Physiotherapy was continued for six weeks. Her major symptoms were relieved except the bell sign which lasted partially even after eight weeks of onset. Score of facial disability index ${ }^{7}$ before $1^{\text {st }}$ physiotherapy treatment session and after last treatment session are expressed in Table-1, and score of Sunnybrook facial grading system ${ }^{8}$ as Table-2. After six more weeks she noticed sudden drooping of eyelid on the affected side. This condition is although occasional but still present.

\begin{tabular}{|l|c|c|}
\hline & $\begin{array}{c}\text { Physical } \\
\text { Functions }\end{array}$ & $\begin{array}{c}\text { Social } \\
\text { Functions }\end{array}$ \\
\hline $\begin{array}{l}\text { Before 1 } \\
\text { Treatment Session }\end{array}$ & 33 & 76 \\
\hline $\begin{array}{l}\text { After Last } \\
\text { Treatment session }\end{array}$ & 105 & 72 \\
\hline
\end{tabular}

Table-1: Score of Facial Disability Index.

\begin{tabular}{|l|c|c|c|c|}
\hline & $\begin{array}{c}\text { Resting } \\
\text { Movements } \\
\text { (Compared to } \\
\text { Normal Side) }\end{array}$ & $\begin{array}{c}\text { Voluntary } \\
\text { Movements } \\
\text { (degree of } \\
\text { Muscle } \\
\text { Excursion } \\
\text { Compared to } \\
\text { Normal Side) }\end{array}$ & $\begin{array}{c}\text { Synkinesis } \\
\text { (Degree of } \\
\text { Involuntary } \\
\text { Movements } \\
\text { associated } \\
\text { with each } \\
\text { expression) }\end{array}$ & $\begin{array}{c}\text { Score } \\
\text { Sorite }\end{array}$ \\
\hline $\begin{array}{l}\text { Before 1 } \\
\text { Treatment } \\
\text { Session }\end{array}$ & $20 / 20$ & $24 / 100$ & $12 / 15$ & 12 \\
\hline $\begin{array}{l}\text { After Last } \\
\text { Treatment } \\
\text { session }\end{array}$ & Zero/20 & $84 / 100$ & $3 / 15$ & 61 \\
\hline
\end{tabular}

Table-2: Scores of Sunnybrook Facial Grading System.

\section{DISCUSSION}

Our study reported the case of left sided facial nerve paralysis in a woman in third trimester of pregnancy, but reported a rare incidence of bilateral facial palsy in pregnant woman in third trimester ${ }^{2}$ which was also reported in a recent case series. ${ }^{5}$ According to another case reported by $\mathrm{N}$ Mathieu et al. in 2011; in a pregnant who had idiopathic facial palsy, pre-eclampsia and HELLP syndrome, there was an association between idiopathic facial palsy which appeared in $3^{\text {rd }}$ trimester and pre-eclampsia, ${ }^{9}$ but in our patient no such finding was observed. A
20 year old white lady was noted with a loss of voluntary movement of right half of upper lip and loss of hearing on same side during her last trimester of pregnancy. On assessment right sided facial paralysis was noted with obscure etiology, ${ }^{10}$ our patient also presented with facial palsy in last trimester.

In 2008, Al-Husban Hassan et al. conducted an investigation in which over a 10 years' time from Jan 1995 to Jan 2005, 36 pregnant females with facial paralysis were found in the ENT and obstetric gynecology facilities at King Hussein Medical Center. The peak time of beginning of facial paralysis was thirty fourth week of gestation and was related with gestational and fetal complications. They reported causes of facial palsy in pregnancy from ten years record, but no information about any of the treatment given was reported, which we considered in our study. Pre-eclampsia was diagnosed in 9 pregnant ladies (25\%), 3 patients presented with gestational hypertension $(8.3 \%)$, the frequency of C-section was $38.9 \%$ (14 patients), and $33.3 \%$ were induced and delivered vaginally (12 patients), $25 \%$ preterm birth (9 patients). Fetal complications included $19.4 \%$ (7 youngsters) of Low Birth Weight (less than $2500 \mathrm{~g}$ ), the rate of congenital anomalies $2.7 \%$ (1 infant), and twin births $5.6 \%$ ( 2 twins). They also inferred that facial paralysis in pregnancy is related with gestational and fetal complications, especially in third trimester. ${ }^{4}$

The strength of our study is that our patient was given an evidence based physiotherapy treatment and was found useful; however none of the previous studies reported any treatment and its outcomes. Moreover, no further complication like Ptosis which our patient suffered afterwards was observed in any of the previous studies. While limitation observed was her anxiety and depressive disorders which resulted in lack of adherence to the prescribed home programme. Another case study reported, Neurodynamics techniques of facial nerve were found effective in the treatment of facial palsy ${ }^{11}$ which is another novel method of treatment and may be considered in females with facial palsy during pregnancy as well. Mazharbadsha et al conducted a randomized controlled trial to study the outcomes of steroids alone and in combination with facial exercise and electrical stimulation on 113 patients with Bell's palsy. They measured the outcomes on House Brackmann facial nerve grading system and found the combination therapy was more useful ${ }^{12}$. Results of our study are in line with the results of this trial. 


\section{CONCLUSION}

Facial palsy can affect any women during pregnancy especially during third trimester. Physiotherapy treatment can help early recovery of the condition.

\section{REFERENCES}

1. Cawthorne T, Haynes D. Facial palsy. British Medical Journal. 1956; 2(5003):1197.

2. Kovo M, Sagi Y, Lampl Y, Golan A. Simultaneous bilateral Bell's palsy during pregnancy. The Journal of Maternal-Fetal \& Neonatal Medicine. 2009; 22(12):1211-3.

3. Cohen Y, Lavie O, Granovsky-Grisaru S, Aboulafia Y, Diamant YZ. Bell palsy complicating pregnancy: a review. Obstetrical \& gynecological survey. 2000; 55(3):184-8.

4. Al-Husen H, Abou-Olim R, Alzbone A, Khreisat M, Al Rawashdeh B. Relationship between the onset of facial palsy during pregnancy and the development of gestational complications.JRMS.2008;15(2):19-22

5. Leelawai S, Sathirapanya P, Suwanrath C. Bell's Palsy in Pregnancy: A Case Series. Case Reports in Neurology. 2020; 12(3):452-9.

6. Gillman GS, Schaitkin BM, May M, Klein SR. Bell's palsy in pregnancy: a study of recovery outcomes. Otolaryngology—Head and Neck Surgery. 2002; 126(1):26-30.

7. VanSwearingen JM, Brach JS. The Facial Disability Index: Reliability and Validity of a Disability Assessment Instrument for Disorders of the Facial Neuromuscular System. Physical Therapy. 1996; 76(12):1288-98.

8. Neely JG, Cherian NG, Dickerson CB, Nedzelski JM. Sunnybrook facial grading system: reliability and criteria for grading. The laryngoscope. 2010; 120(5):1038-45.

9. Mathieu N, Ledigabel J. Pre-eclampsia and facial paralysis. Gynecologie, obstetrique \& fertilite. 2011; 39(2):e31-3

10. STORY SR. Conductive deafness, seventh nerve paralysis, and absence of vestibular response during pregnancy. AMA archives of otolaryngology. 1958; 68(5):632-3.

11. Kashoo FZ, Alqahtani M, Ahmad M. Neural mobilization in Bell's palsy: A case report. CRANIO®. 2019:1-4.

12. Badshah M, Umar M, Naeem A, Marryam M. A Randomized Control Trial to Review the
Effectiveness of Combination Therapy versus Steroids Alone, for the Treatment of Bells Palsy. Ann Pak Inst Med Sci. 2013; 9(3):118-21.

\section{The Authors:}

Wajida Perveen

Associate Professor,

HOD, Programme Director DPT,

Sialkot College of Physical Therapy,

Amin Welfare \& Teaching Hospital, Sialkot.

Muhammad Akhtar

Associate Professor,

Department of Physical Therapy,

University of Lahore.

Riaz Hashmi

Incharge,

Department of Physical Therapy,

Syed Medical Complex, Sialkot.

Misbah Amanat Ali

Assistant Professor,

Department of Physical Therapy,

Sialkot College of Physical Therapy,

Amin Welfare \& Teaching Hospital, Sialkot.

Sahreen Anwar

Assistant Professor,

Department of Physical Therapy,

Independent Medical College, Faisalabad

Dr. Ayesha Ghani

PG Trainee,

Department of Gynecology \& obstetrics

Madina Teaching Hospital, Faisalabad.

\section{Corresponding Author:}

Wajida Perveen

Associate Professor,

HOD, Programme Director DPT,

Sialkot College of Physical Therapy,

Amin Welfare \& Teaching Hospital, Sialkot.

E-mail: wajopri@gmail.com 